\title{
Attachment Style and the Mental Representation of the Self
}

\author{
Mario Mikulincer \\ Bar-Ilan University
}

\begin{abstract}
Six studies examined the association between attachment style and several aspects of the mental representation of the self in adolescents. Studies 1 and 2 focused on the hedonic tone of the selfstructure, Studies 3 and 4 focused on its complexity, and Studies 5 and 6 focused on discrepancies between domains and standpoints of the self. Results indicated that secure and avoidant persons had a more positive view of themselves than anxious-ambivalent persons. In addition, secure persons were found to have a more balanced, complex, and coherent self-structure than insecure persons, either avoidant or anxious-ambivalent. The discussion emphasizes the connection between the internalization of attachment experiences and the construction of the self.
\end{abstract}

Research on adult attachment uses Bowlby's (1973) construct of working models-mental representations of attachment figures and the self-to explain how past interactions with significant others influence social and emotional development. Initial studies of adult attachment focused on the way people think about and behave in their relationships (e.g., Hazan \& Shaver, 1987). The present series of studies focuses on a neglected aspect of attachment working models: the mental representation of the self.

\section{Attachment Theory and Research}

Attachment theory (Bowlby, 1969, 1973, 1980) proposes that the quality of infant-caregiver interactions results in mental working models that organize cognitions, affects, and behavior in later relationships; guide affect regulation; and shape selfimage. Following these ideas, Hazan and Shaver (1987) examined attachment working models in adults, using the tripartite classification of infant attachment style (Ainsworth, Blehar, Waters, \& Wall, 1978). The secure style is defined by confidence in the availability of attachment figures in times of need, comfort with closeness, interdependence, and trust. The avoidant style is characterized by insecurity in others' intentions and preference for emotional distance. The anxious-ambivalent style portrays a strong desire for intimacy together with insecurity about others' responses to this desire and high fear of rejection. Hazan and Shaver (1987) found that self-reports of adult attachment style were related to reports of parent-child attachment. Adults who defined themselves as secure in their close relationships reported more secure interactions with their parents than adults who described themselves as insecure, either avoidant or anxious-ambivalent.

Building on Hazan and Shaver's (1987) work, a wealth of studies have assessed several correlates of adult attachment

Correspondence concerning this article should be addressed to Mario Mikulincer, Department of Psychology, Bar-Ilan University, Ramat Gan 52900, Israel. Electronic mail may be sent via Bitnet to F41345@BARILAN. style. Attachment groups have been found to differ in perceptions, expectations, and functioning in close relationships (e.g., Brennan \& Shaver, in press; Feeney \& Noller, 1990; Mikulincer \& Erev, 1991; Pietromonaco \& Carnelley, 1994). In addition, attachment style has been found to be related to affect regulation (Mikulincer, Florian, \& Tolmacz, 1990; Mikulincer, Florian, \& Weller, 1993; Mikulincer \& Orbach, 1995; Simpson, 1990; Simpson, Rholes, \& Nelligan, 1992). Secure people seek social support in times of need and rely on constructive coping strategies to regulate affect. Insecure people rely on less constructive ways of coping and are less able at regulating affect. Whereas avoidant people rely on repressive and withdrawal strategies, anxious-ambivalent people rely on emotion-focused coping that increases rather than decreases distress.

The present study examines Bowlby's (1973) idea that attachment experiences shape a person's self-image. In his words, people rely on attachment experiences as a source of information for learning about themselves. Sroufe and Fleeson (1986) proposed that components of the attachment figures are incorporated into the self through the learning of roles within the relationship. Thus, the more people feel secure in their relationships, and the more they feel valued by others, the more they come to feel valuable and special. Conversely, people who feel rejected by others may feel worthless and of little value.

Four adult attachment studies support the above hypothesis (Bartholomew \& Horowitz, 1991; Collins \& Read, 1990; Feeney \& Noller, 1990; Griffin \& Bartholomew, 1994). Secure adults have been found to have higher self-esteem than anxiousambivalent people. With regard to avoidant adults, the findings are more ambiguous. Although Feeney and Noller (1990) and Griffin and Bartholomew (1994) found that avoidant people have a more negative self-image than secure people, Collins and Read (1990) found no difference between these two groups.

The problem with the above studies is that they focused on a single aspect of the self-system: self-esteem. This is a narrow view that ignores the complexity of the self-construct. In fact, these studies did not address current definitions of the self as a cognitive structure (e.g., Kihlstrom \& Cantor, 1984; Markus \& Wurf, 1987; Rogers, 1981), which is assumed to include a large number of self-relevant data that are organized into a 
hierarchy of representations, each one reflecting a more or less inclusive aspect of the self. Moreover, they did not take into account Higgins' (1987) hypothesis that each self-representation includes information about different domains of the self (e.g., actual, ideal) and standpoints of the self (the person's own view, others' views). The present series of studies attempts to provide information on the association between attachment style and the following aspects of the self-structure: (a) the content of the attributes that people use in thinking about themselves, (b) the organization of these attributes into self-representations, and (c) the correspondence between domains and standpoints of the self.

\section{Attachment Style and the Self-Structure}

\section{Hedonic Value}

The first set of hypotheses concerns the habitual hedonic valence of the self-structure. When thinking about themselves, people may use positive and negative attributes that would determine the hedonic tone of their self-appraisal and their subsequent responses (e.g., Markus, 1977; Markus \& Wurf, 1987). This hedonic tone may vary within the person across situations and over time, depending on the attributes that become accessible in the self-structure by a real experience or by associations with other attributes (Markus, 1977). However, it may also vary among individuals; some people habitually think of themselves in positive terms, whereas others describe themselves in negative terms. These individual differences are directly reflected in the person's self-esteem and chronic mood (Bargh \& Tota, 1988; Beck, 1976; Segal, 1988; Segal \& Vella, 1990).

I hypothesized that people differing in attachment style would differ in the hedonic tone of their self-structure. Secure people, who felt valued by their attachment figures (Shaver \& Hazan, 1993), would think of themselves in positive terms. This is not to say that they cannot admit weak points of their self but that positive attributes would be more available in their self-structure. In contrast, anxious-ambivalent people, who grew up with doubts about their value in the eyes of significant others, would tend to use negative attributes when thinking about themselves. With regard to avoidant people, one could argue that their insecure attachment experiences would also be reflected in a negative self-view. However, avoidant people would have a more positive view of themselves because they cope with their insecurity by suppressing any thought that brings their weaknesses to mind (Mikulincer et al., 1993).

\section{Self-Complexity}

The second set of hypotheses concerns self-complexity. Following Schroder, Driver, and Streufert (1967), Streufert and Streufert (1978), and Tetlock and Suedfeld (1988), I consider the self-structure to be complex to the extent that it is characterized by a large number of differentiated self-aspects and the integration of these self-aspects. Thus, high self-complexity consists of a high degree of differentiation and a high degree of integrative organization.

Differentiation refers to the number of self-aspects (e.g., "myself as a student") that a person uses for organizing information and to their degree of distinctiveness-the extent to which selfaspects include nonoverlapping information (Linville, 1985; Tetlock, 1983; Woike, 1994). Highly differentiated people organize their experiences through a large number of narrow, context-specific self-aspects. These people can distinguish between different parts of the self and analyze information using different perspectives. Less differentiated people categorize information into few, redundant self-aspects. These people have few options for analyzing information, and they are unable to prevent the spreading of the impact of experience with respect to one self-aspect to other aspects. Low differentiation has been found to be related to affective extremity and the spreading of negative affect over the self-structure (Linville, 1985).

Integration refers to the development of complex connections among differentiated self-aspects (Tetlock \& Suedfeld, 1988). Highly integrated people possess superordinate categories that connect among the different self-aspects without canceling their uniqueness and contradictions. They can compare among selfaspects, appraise their interactions, confront trade-offs, and cope with contradictions in the self-structure. Less integrated people might have a fragmented self-structure, in which different self-aspects are like islands that have no relation or influence among them. These people cannot tolerate ambiguities and contradictions and tend to remain "stuck" in conflictual situations ( Tetlock, Peterson, \& Berry, 1993).

I hypothesized that anxious-ambivalent people would show lower differentiation of the self than secure and avoidant people. This difference may result from one source of self-differentiation: the pervasiveness of affect in self-structure (Pietromonaco, 1985). Pietromonaco stated that the self not only regulates affect but also its structure (e.g., level of differentiation ) may be shaped by the way people experience and react to affect. Anxious-ambivalent people, who experience negative affect intensely and focus obsessively on their emotions (Shaver \& Hazan, 1993), may become attuned to the affective nature of the information and consequently may organize their self-structure largely by using a simple affective criterion (whether the information makes one feel good or bad). This tendency may lead to the sorting of self-attributes into few, general affective categories, therefore resulting in low self-differentiation.

Secure people, who are able to prevent the spillover of negative affect (Mikulincer \& Orbach, 1995), may sort information also according to other nonaffective criteria. They would sometimes rely on affective criteria and in other times encode information according to more narrow, context-specific content domains. That is, they could diversify the criteria that underlie the self-structure and thus show high self-differentiation. The same pattern may be shown by avoidant persons, who have been found to distance from any affective experience (Shaver \& Hazan, 1993). Along this reasoning, differences among attachment groups in self-differentiation should parallel differences in the pervasiveness of affect in self-organization. These differences will also be examined in the present study.

With regard to the integration of the self, I hypothesized that it would be higher among secure people than among avoidant or anxious-ambivalent people. According to attachment theory, a "secure base" allows people to admit frustrating aspects of their experience and weak points of their self (Bowlby, 1988; 
Sroufe \& Fleeson, 1986). Moreover, it enables the incorporation of negative information into the self-structure so that people can understand the meaning of this information and cope with its consequences (Cassidy, 1988). In this way, secure people can recognize that their self includes both good and bad aspects that, despite their opposed implications, may coexist in harmony and may interact in shaping behavior. This confidence to reveal and synthesize strong and weak aspects of the self may be the germ for the growth of a highly integrative self-structure.

Along the same reasoning, the lack of a secure base may result in so fragile a self-view that people may be precluded from acknowledging negative experiences and revealing personal imperfections without feeling overwhelmed by them (Cassidy, 1988 ). Whereas avoidant people habitually deny negative experiences and suppress negative memories (Kobak \& Sceery, 1988; Mikulincer \& Orbach, 1995), anxious-ambivalent people are so overwhelmed by the negative aspects of their experience that they cannot recognize other positive aspects (e.g., Mikulincer \& Orbach, 1995). In either case, the two insecure groups may be unable to admit that good and bad self-aspects can coexist in harmony and to tie them together in an integrative structure.

\section{Self-Discrepancies}

The third set of hypotheses concerns the matching among different facets of the self. As stated earlier, people encode information about different facets of the self. Higgins (1987) classified these facets according to two dimensions: domains of the self and standpoints on the self. The basic domains are the actual self-the attributes that someone believes the person possesses, the ideal self-the attributes that someone would like the person to possess, and the ought self-the attributes that someone believes the person should possess. The basic standpoints are the person's own view of his- or herself and his or her belief about the way significant others perceive him or her.

According to Higgins (1987), people are motivated to minimize discrepancies among different facets of the self. He also proposed that a discrepancy between two facets produces discomfort and that different kinds of discrepancy produce different types of distress. In support of this view, Higgins, Klein, and Strauman (1985), Higgins, Bond, Klein, and Strauman (1986), and Strauman and Higgins (1987) found that a discrepancy between actual and ideal selves was related to shame and depression, and a discrepancy between actual and ought selves was associated with anxiety, guilt, and fear of punishment.

My basic hypothesis was that avoidant and anxious-ambivalent people would show higher actual-ideal and actual-ought self-discrepancies than would secure people. According to Higgins (1987), children internalize parents' ideal-ought guidelines for them and try to meet these standards to avoid punishment and to achieve positive outcomes (e.g., parent's love). However, the meeting of these guidelines also depends on parents' responses to their children. On the one hand, children who feel loved and accepted by their parents may come to believe that they meet the internalized guidelines and may develop an actual self that matches their ideal-ought selves. This is the case of secure people who grew up in a warm and accepting family milieu. On the other hand, children who are criticized or rejected by their parents may feel that they fail in avoiding negative outcomes or achieving positive ones and may develop actual selves that are discrepant from their self-guides. This is the case of insecure people who have experienced frustrating and negative interactions with their parents (e.g., Shaver \& Hazan, 1993).

The above sets of hypotheses were examined in six studies. Studies 1 and 2 focused on the hedonic tone of self-structure, Studies 3 and 4 examined the complexity of self-structure, and Studies 5 and 6 focused on self-discrepancies. In the six studies, high school students completed Hazan and Shaver's (1987) scale of attachment style and other material tapping the assessed aspects of the self-structure. In the six studies, all the participants had experienced at least one romantic relationship, and they answered the attachment scale with regard to their romantic experiences.

\section{Study 1}

Study 1 examined differences among attachment groups in the hedonic tone of self-structure, as measured by the self-referent encoding task (SRET; Derry \& Kuiper, 1981; Kuiper \& Derry, 1982). Participants were asked to decide whether a number of positive and negative adjectives were self-descriptive. Then an incidental recall test of the adjectives was administered. The assumption underlying the recall test is that adjectives that are accessible in the self-structure would produce higher incidental recall than adjectives irrelevant to the selfschema (Rogers, 1981). I predicted that secure and avoidant people would choose and recall more positive and fewer negative self-attributes than would anxious-ambivalent people.

\section{Method}

Participants. One hundred and three high school students (61 females and 42 males ranging in age from 16 to 18 ) volunteered to participate in the study without monetary reward.

Materials and procedure. Participants were approached in classrooms and were tested in group sessions containing up to 30 individuals. They were told that they would participate in a study on self-perception. The order of the questionnaires was counterbalanced.

Attachment style was assessed by asking participants to read Hazan and Shaver's (1987) three descriptions of attachment styles and to endorse the description that best described their feelings.' Sixty-three percent of the participants $(N=65)$ classified themselves as securely attached, $24 \%$ as avoidant $(N=25)$, and $13 \%$ as ambivalent $(N=13){ }^{2}$

\footnotetext{
${ }^{1}$ Participants also answered the 15 -item three-factor attachment scale (see Mikulincer et al., 1990, for details) and were assigned to the attachment style that had the highest value on the scale. In all the studies, there were less than $10 \%$ of mismatches between the two classification techniques. In cases of mismatches, participants were assigned to the style that they themselves had chosen. Statistical analysis demonstrated that the exclusion of mismatches from the sample made no change in the results of all the studies.

${ }^{2}$ No gender difference in the distribution of attachment styles was found in all the studies. In addition, results of all the studies did not change when gender was introduced as a covariate, and no significant Attachment $\times$ Gender interaction was found.
} 
The version of the SRET used in this study was similar to that used by Kuiper, Olinger, MacDonald, and Shaw (1985). Participants received a list of 30 positive adjectives and 30 negative, depression-relevant adjectives, drawn from Kuiper and Derry's (1982) work and translated into Hebrew by two bilingual psychologists. Pretests with Israeli participants demonstrated that positive and negative adjectives indeed differed in their hedonic value but not in their imagery value, word length, and word frequency. Participants were instructed that they would hear a list of adjectives and were asked to rate whether or not each adjective describes them. Then they were provided with a rating sheet containing 60 cue questions ("Does this adjective describe you?"); each adjective was read aloud by the experimenter, and participants made a yes-no decision on the rating sheet beside the corresponding cue question. The 60 adjectives were read in a random order. After all the 60 adjectives were read, participants were unexpectedly given $3 \mathrm{~min}$ to recall as many of the adjectives as possible, in any order they could. Participants wrote down the adjectives on the back of their rating sheets.

\section{Results and Discussion}

Self-referent judgments. The number of yes decisions in each adjective category (negative, positive) was analyzed with a two-way analysis of variance (ANOVA) for Attachment Style $X$ Adjective category. The last variable was a within-subject repeated measure. The ANOVA yielded a significant main effect for adjective category, $F(1,100)=936.77, p<.01$, such that participants made more yes decisions for positive traits $(M=22.37)$ than for negative traits $(M=5.26)$. The Attachment Style $\times$ Adjective Category interaction also was significant, $F(2,100)=13.06, p<.01$. A test for simple main effects (Winer, 1971) and Scheffe tests showed that anxious-ambivalent participants endorsed more negative $(M=8.92)$ and fewer positive traits $(M=19.00)$ than secure participants ( $M s=$ 4.25 and 23.05 for negative and positive traits, respectively) and avoidant participants $(M \mathrm{~s}=6.00$ and 22.40$) ; F(2,100)$ $=9.44, p<.01$ for negative traits, and $F(1,100)=5.58, p<$ .01 , for positive traits. No difference was found between secure and avoidant groups.

Self-referent recall. The recall data were analyzed on the basis of Kuiper et al.'s (1985) procedure. Kuiper et al. assumed that positive self-referent recall includes the recall of positive traits that are endorsed as self-relevant in the SRET (yes rating) and negative traits that are not endorsed as self-relevant (no rating). Both are positive in the sense that participants judge themselves as possessing positive traits but not as possessing negative attributes. Accordingly, negative self-referent recall includes the recall of negative traits that receive a yes rating (possessing negative traits) and positive traits that receive a no rating (not possessing a positive trait).

On this basis, a positive score was computed by averaging two proportions: (a) recalled yes-rated positive words/total yesrated positive words, and (b) recalled no-rated negative words/ total no-rated negative words. Accordingly, a negative score was computed by averaging two proportions: (a) recalled yes-rated negative words/total yes-rated negative words, and (b) recalled no-rated positive words/total no-rated positive words. Then a positivity recall score was computed by subtracting the negative score from the positive score.

A one-way ANOVA yielded a significant effect for attachment style on the positivity recall score $F(2,100)=6.95, p<.01$. Scheffe tests $(\alpha=.05)$ revealed that anxious-ambivalent participants had a lower positivity recall score $(M=.30)$ than did secure participants $(M=.58)$. Avoidant participants $(M=.46)$ did not significantly differ from secure participants. ${ }^{3}$

The findings show that the self-schema of ambivalent people is more negative than that of secure people: They described themselves in more negative terms, and their self-referent recall was more negative. As expected, the positivity of the selfschema of avoidant people did not differ from that of secure people. However, note that the above findings may also reflect avoidant people's response style (Ferguson, Rule, \& Carlson, 1983 ) or a social desirability bias. These problems are addressed in Study 2, which examined the hedonic tone of selfstructure while weakening the influence of response set.

\section{Study 2}

Study 2 also assessed the hedonic tone of the self-structure of attachment groups while addressing some of the confounds identified in the SRET. In this study, participants were not explicitly asked to think about their self-attributes, rather, they performed a self-irrelevant task (color-naming) while ignoring these attributes. Here, the hedonic tone of the self-structure was not tapped by the number of accessible positive and negative self-attributes but by the extent to which these attributes are automatically activated in the working memory and interfere with task performance (e.g., Segal, 1988).

Specifically, I used a modification of the Stroop Color-Naming task (Stroop, 1938). Participants were asked to name the color in which positive and negative self-attributes were written. Color-naming is known to be slowed when the representations of the words to be color-named are automatically activated and compete with color-naming for processing resources (e.g., Warren, 1972). Research has also revealed that the color-naming of traits that are chronically accessible in the self-structure is slower than that of traits irrelevant to one's self-view (e.g., Mathews \& MacLeod, 1985). The former are likely to be automatically activated during their presentation in the Stroop task and then to interfere with color-naming. Given these findings, I predicted that anxious-ambivalent people would show longer colornaming latencies for negative self-attributes than for other word categories. In contrast, secure and avoidant people would show longer latencies for positive self-attributes than for other word categories.

\section{Method}

Participants. Sixty high school students ( 30 females and 30 males ranging in age from 16 to 18 ) participated in the study without any reward.

Materials and procedure. Participants were tested individually on two occasions. In the first session, a large sample of 169 participants completed the attachment style scale (see Study 1). Fifty-eight percent

\footnotetext{
${ }^{3}$ Similar results were found when ANOVAs were performed on the positive and negative recall scores as well as on each of the computed proportion scores.
} 
Table 1

Means and SDs of Color-Naming Latencies According to Type of Trait and Attachment Style (Study 2)

\begin{tabular}{|c|c|c|c|c|c|c|}
\hline \multirow[b]{3}{*}{ Type of trait } & \multicolumn{6}{|c|}{ Attachment style } \\
\hline & \multicolumn{2}{|c|}{ Secure } & \multicolumn{2}{|c|}{ Avoidant } & \multicolumn{2}{|c|}{ Ambivalent } \\
\hline & $M$ & $S D$ & $M$ & $S D$ & $M$ & $S D$ \\
\hline \multicolumn{7}{|l|}{ Self-relevant } \\
\hline $\begin{array}{l}\text { Positive } \\
\text { Negative }\end{array}$ & $\begin{array}{l}82.60^{\mathrm{a}} \\
79.25^{\mathrm{a}}\end{array}$ & $\begin{array}{l}13.23 \\
12.71\end{array}$ & $\begin{array}{l}92.00^{\mathrm{b}} \\
67.80^{\mathrm{b}}\end{array}$ & $\begin{array}{l}10.93 \\
14.92\end{array}$ & $\begin{array}{l}69.15^{\mathrm{a}, \mathrm{b}} \\
84.85^{\mathrm{a}}\end{array}$ & $\begin{array}{l}10.15 \\
12.19\end{array}$ \\
\hline \multicolumn{7}{|l|}{ Self-irrelevant } \\
\hline Positive & 64.85 & 8.97 & 65.75 & 9.46 & 67.00 & 10.51 \\
\hline Negative & 66.90 & 11.39 & 65.40 & 8.19 & 67.85 & 11.96 \\
\hline
\end{tabular}

a Significantly different from avoidant participants.

${ }^{b}$ Significantly different from secure participants.

of the participants classified themselves as secure $(N=98), 27 \%$ as avoidant $(N=46)$, and $15 \%$ as ambivalent $(N=25)$. To generate the item pool for the Stroop task, participants also rated the extent to which the 60 traits described in Study 1 were self-descriptive. Ratings were made on a 4-point scale ranging from 1 ( a little) to 4 (extremely).

In the second session, 1 week later, 60 participants -20 secure, 20 avoidant, and 20 ambivalent-were randomly selected (within each group) to complete a version of the Stroop color-naming task (Mathews \& MacLeod, 1985). The three attachment groups included equal numbers of men and women. Participants named the colors of words printed on four 20 -line cards. On each card $(56 \mathrm{~cm} \times 70 \mathrm{~cm})$ was printed a set of five words that were repeated 20 times throughout the card and printed in five different colors ( pink, green, black, orange, blue). The words ( $1 \mathrm{~cm}$ high) were written with marking pens and appeared randomly on the 20 lines of a card. Words were randomized within pairs of lines so that a word appeared twice in two lines (although not sequentially). Ink color was randomly assigned to the words in the same manner.

The set of words used in the cards was different for each participant and was selected from their self-referent judgments. The cards were: (a) self-relevant negative card-five negative adjectives that a participant rated as highly self-descriptive (received a rating of 3 or 4 ), (b) a control negative card - five negative adjectives that a participant did not choose as descriptive of his- or herself (received a rating of 1 ), (c) a self-relevant positive card-five positive adjectives that a participant rated as highly self-descriptive (ratings of 3 or 4), and (d) a control positive card-five positive adjectives that a participant did not choose as self-descriptive (rating of 1 ).

The experimenter told participants that they would perform a perceptual task. They were instructed to name aloud the word colors as quickly and accurately as possible. They were told that they would be timed with a stopwatch. For each of the cards, the experimenter began timing when the first color name was announced and stopped at the last color name. The four cards were presented in a random order. ${ }^{4}$

\section{Results and Discussion}

Color-naming latencies were analyzed with a three-way ANOVA for attachment style, self-relevance of the card (selfrelevant or control), and valence of the card (negative or positive). The two last variables were treated as within-subject measures. Table 1 presents relevant means and standard deviations of color-naming latencies (in seconds).
The ANOVA revealed a significant main effect for self-relevance of the card, $F(1,57)=69.49, p<.01$, with self-relevant cards having longer color-naming latencies $(M=79.27 \mathrm{~s})$ than control cards $(M=66.29 \mathrm{~s})$. The three-way interaction also was significant, $F(1,57)=19.17, p<.01$. Tests for simple main effects and Duncan tests for repeated measures revealed that secure people took longer time to name the colors of self-relevant words, either positive or negative, than those of control words, $F(3,57)=28.58, p<.01$. Avoidant people took longer time to name the colors of self-relevant positive words than those of other word categories, $F(3,57)=18.30, p<.01$. Anxious-ambivalent people took longer time to name the colors of self-relevant negative words than those of other word categories, $F(3,57)=10.94, p<.01$.

In addition, anxious-ambivalent and secure people showed longer latencies in the self-relevant negative card than did avoidant people, $F(2,57)=8.51, p<.01$. Avoidant people showed longer latencies in the self-relevant positive card than secure people, who, in turn, showed longer latencies than anxious-ambivalent people, $F(2,57)=19.90, p<.01$. No significant group difference was found in the control cards.

The results strengthen the conclusions of Study 1 . The negative self-view of ambivalent participants was manifested in the interference produced by negative self-attributes, whereas the positive self-view of avoidant participants was manifested in the interference produced by positive self-attributes. Interestingly, though secure people described themselves in more positive than negative terms (Study 1), both types of self-attributes appear to be accessible in their self-structure and to interfere with color-naming. That is, these people may incorporate into their self-schema both positive and negative traits, but the overt description of themselves is biased by some self-presentation ten-

\footnotetext{
${ }^{4}$ Before ending the experiment, participants were asked to recognize any of the words that they thought had appeared on the cards from a list of target and distraction words (Mathews \& MacLeod, 1985). No significant difference was found in the accuracy of recognition among attachment groups. This finding implies that the observed differences in color-naming latencies were not associated with differences in awareness of word content and recognition memory.
} 
dencies. Of course, the findings tell nothing about the mechanism of the interference effect. They only suggest that attachment groups differ in the type of attributes that are active in self-structure.

\section{Study 3}

Study 3 examined differences among attachment groups in two aspects of the organization of the self-structure: cognitive differentiation and the pervasiveness of affect. For this purpose, participants completed a trait-sort task (Linville, 1985; Pietromonaco, 1985) in which they were asked to sort positive, negative, and neutral traits into categories that described different aspects of themselves. Then participants were asked to supply a label that described the content or meaning of each of the categories. The number and distinctiveness of the categories created served as measures of self-differentiation, whereas the labels provided for these categories tapped whether the categorization was made on the basis of affective or nonaffective criteria. I predicted that anxious-ambivalent people would show lower self-differentiation scores and provide more affective labels for their self-representations than would secure and avoidant people.

\section{Method}

Participants. Eighty high school students ( 51 females and 29 males ranging in age from 15 to 17 ) participated in the study without any reward.

Materials and procedure. Participants were individually invited to participate in a study on self-perception. They completed the attachment style scale (see Study 1) and a trait-sort task in a random order. Sixty-three percent of the participants classified themselves as secure $(N=50), 20 \%$ as avoidant $(N=16)$, and $17 \%$ as ambivalent $(N=14)$.

In the trait-sort task, participants received a packet of 88 randomly ordered cards, each containing the name of a trait drawn from Anderson's (1968) list of personality trait adjectives and translated into $\mathrm{He}$ brew by Himelfarb (1970). The positivity or negativity of the traits was determined by Israeli norms of Anderson's likability ratings (Himelfarb, 1970). Thirty-three traits with likability ratings of less than 257 (e.g., worried), 33 traits with likability ratings of greater than 311 (e.g., generous), and 22 traits with ratings between 257 and 311 (e.g., talkative) were classified as negative, positive, and neutral, respectively.

Participants received the cards and were asked to think about themselves and "to sort those traits that are descriptive of you into groups according to which traits you think belong together." Participants were told that traits could be sorted on any meaningful basis and that each group might represent a different aspect of the self. They were also told that they could form as many or as few groups as they found meaningful, that a trait could be placed in more than one group, and that they did not have to use every trait. After completing the sorting task, participants were asked to give a name to each group of traits ("label the particular aspect of yourself represented by each group").

\section{Results and Discussion}

Self-differentiation. Two differentiation scores were computed for each participant: (a) the number of self-aspects (categories) that participants differentiated in describing themselves, and (b) the degree of distinctiveness of the above selfaspects-the mean proportion of attributes that were exclu- sively sorted in a self-aspect (and not in the others) from the total number of attributes sorted in that aspect. Higher scores indicate higher differentiation and higher distinctiveness of selfaspects.

One-way ANOVAs yielded significant effects of attachment style on the number of self-aspects, $F(2,77)=6.13, p<.01$, and on the distinctiveness score, $F(2,77)=9.41, p<.01$. As expected, Scheffe tests indicated that anxious-ambivalent participants sorted self-attributes into fewer self-aspects than avoidant participants ( see means in Table 2). The secure group did not significantly differ from the other two groups. Accordingly, these tests also revealed that anxious-ambivalent participants constructed fewer differentiated categories than avoidant and secure participants. No significant difference was found between avoidant and secure participants.

Pervasiveness of affect. The labels of the categories were content-analyzed by two judges (graduate psychology students) who were unaware of the attachment style of the participants. Judges read each label and coded it as expressing either positive affect ("traits I like about myself"), negative affect ("my bad qualities"), mixed affect ("my strengths and weaknesses"), or nonaffective themes ("my academic aptitudes"). This procedure was similar to that used by Pietromonaco (1985). The judges agreed in more than $95 \%$ of the cases. When a mismatch was found, I decided about the type of the label.

The proportion of each type of label to the total number of categories formed was analyzed with one-way ANOVAs for attachment style (see means in Table 2). Attachment style had significant effects only on the proportions of negative affect labels, $F(2,77)=4.78, p<.05$, and nonaffective labels, $F(2,77)$ $=4.17, p<.05$. Scheffé tests indicated that anxious-ambivalent participants used fewer nonaffective themes and more negative affect themes than did secure and avoidant participants.

The findings were in line with our predictions. The self-structure of anxious-ambivalent people was found to be pervaded by negative affective experience, which, in turn, may explain their tendency to organize self-relevant information into few, overlapping categories. In contrast, secure and avoidant people were found to diversify the criteria for organizing self-relevant information, which, in turn, may be one of the precursors of their highly differentiated self-structure. Note that it is not yet known whether attachment groups differ in the mechanism and meaning of the differentiation process. ${ }^{5}$

\section{Study 4}

Study 4 examined whether attachment groups differ in the integration of self-structure. Participants were asked to think about two different self-aspects (e.g., "I as a student," "I as a friend") and to list a number of distinctive traits for each of them. Scores of integration were obtained by asking participants to rate the similarity, mutual influence, trade-off, and joint interaction between traits of different self-aspects. These

\footnotetext{
${ }^{5}$ Similar results were found when the ANOVA was performed on the $H$ score (Linville, 1985) -a score that reflects the minimal number of independent attributes needed to reproduce the trait sort.
} 
Table 2

Means and SDs of Number, Distinctiveness, and Labels of Self-Aspects According to Attachment Style (Study 3)

\begin{tabular}{|c|c|c|c|c|c|c|}
\hline \multirow[b]{3}{*}{ Sort task measures } & \multicolumn{6}{|c|}{ Attachment style } \\
\hline & \multicolumn{2}{|c|}{ Secure } & \multicolumn{2}{|c|}{ Avoidant } & \multicolumn{2}{|c|}{ Ambivalent } \\
\hline & $M$ & $S D$ & $M$ & $S D$ & $M$ & $S D$ \\
\hline \multicolumn{7}{|l|}{ Differentiation scores } \\
\hline Number & 3.07 & 1.44 & 3.69 & 1.30 & $2.64^{\mathrm{a}}$ & 0.83 \\
\hline Distinctiveness & 60.68 & 11.88 & 67.70 & 10.64 & $49.93^{\mathrm{a}, \mathrm{b}}$ & 9.39 \\
\hline \multicolumn{7}{|l|}{ Proportions of labels } \\
\hline Positive affect & 0.16 & 0.21 & 0.14 & 0.16 & 0.20 & 0.21 \\
\hline Negative affect & 0.11 & 0.19 & 0.12 & 0.15 & $0.31^{\mathrm{a}, \mathrm{b}}$ & 0.30 \\
\hline Mixed affect & 0.08 & 0.15 & 0.04 & 0.13 & 0.15 & 0.29 \\
\hline Nonaffective & 0.65 & 0.38 & 0.70 & 0.31 & $0.34^{\mathrm{a}, \mathrm{b}}$ & 0.40 \\
\hline
\end{tabular}

Significantly different from avoidant participants.

b Significantly different from secure participants.

ratings have been regarded in previous studies as representing the main dimensions of cognitive integration (e.g., Tetlock, 1983; Woike, 1994; Woike \& Aronoff, 1992). The main prediction was that secure participants would show higher integration scores than would avoidant and ambivalent participants.

\section{Method}

Participants. Sixty high school students ( 32 females and 38 males ranging in age from 16 to 18 ) participated in the study without any reward.

Materials and procedure. Participants were tested individually on two occasions. In the first session, a large sample of 167 participants completed the attachment style scale (see Study 1). Sixty-one percent of the participants classified themselves as secure $(N=98), 25 \%$ as avoidant $(N=46)$, and $14 \%$ as ambivalent $(N=23)$.

In the second session, 1 week later, 60 participants -20 secure, 20 avoidant, and 20 ambivalent-were randomly selected (within each group) to complete a number of self-referent judgments. Participants were asked to choose two very different aspects of their personal experience and to think about themselves in each of these aspects. Then they wrote, in a free format, five traits for each of the two self-aspects. Participants were told that traits should characterize one of the chosen selfaspects and should not appear in the other aspect. That is, they should be distinctive features of a self-aspect.

After listing the 10 traits, participants rated, on a 7-point scale that ranged from not at all (1) to very much (7), the extent to which a trait that defines one self-aspect is likely to appear in the other aspect. These 10 ratings served as a manipulation check of the differentiation between the two self-aspects. All the ratings were lower than 3 , implying that the integration ratings described below were made on differentiated selfaspects. Moreover, no significant difference was found among attachment groups on these scores.

Participants then received $5 \times 5$ matrices; each dimension included the traits of one self-aspect. In the horizontal dimension, participants wrote the traits of the first chosen self-aspect $(A)$. In the vertical dimension, participants wrote the traits of the second self-aspect $(B)$. Then they made the following randomly ordered ratings on 7-point scales, ranging from not at all (1) to very much (7):

1. The extent to which a pair of traits from different self-aspects have similar manifestations in overt behaviors. On the basis of their appro- priate internal consistency (Cronbach's $\alpha=.92$ ), the 25 ratings were averaged into a global score labeled similarity.

2. The extent to which changes in a trait of one self-aspect (e.g., being more responsible) can produce similar changes in a trait of the other self-aspect (e.g., being more sociable). Participants rated all 25 pairs of traits twice. They first rated the causal influence of traits of self-aspect $A$ and then rated the influence of traits of self-aspect $B$. Having appropriate internal consistency (Cronbach's $\alpha=.84$ ), the 50 ratings were averaged into a global score labeled mutual influence.

3. The extent to which a positive change in a trait of one self-aspect would cause a negative change in a trait of the other self-aspect (e.g., being more responsible as a student at the cost of being less sociable as a friend). Participants rated all the pairs of traits twice: for positive changes of traits of self-aspect $A$ and for positive changes of traits of selfaspect $B$. On the basis of their appropriate internal consistency (Cronbach's $\alpha=.82$ ), the 50 ratings were averaged into a global score labeled trade-offs.

4. The extent to which a trait of one self-aspect interacts with a trait of the other self-aspect in determining behavior. Participants rated all the pairs of traits twice: for behaviors that were related to self-aspect $A$ and for behaviors that were related to self-aspect $B$. The 50 ratings had high internal consistency (Cronbach's $\alpha=.93$ ) and thus were averaged into a global score labeled joint interaction.

The mutual influence, trade-off, and joint interaction scores were highly correlated ( $r$ s ranging from .53 to .68 ). The correlations of the similarity score with the other three scores were lower but also statistically significant ( $r$ s ranging from .24 to .29 ). With the exception of the similarity score, it seems that the other three scores represent related dimensions of self-integration.

\section{Results and Discussion}

As can be seen in Table 3, the multivariate ANOVA revealed a significant effect of attachment style, $F(8,108)=2.51, p<$ .05 . This effect was significant in the mutual influence, tradeoff, and joint interaction scores ( $\operatorname{see} F$ ratios in Table 3 ). Scheffe tests indicated that secure participants reported higher mutual influence, trade-offs, and joint interactions between the two differentiated self-aspects than did avoidant and ambivalent participants ( see means in Table 3). Significant differences were not found between the two insecure groups. 
Table 3

Means, SDs, and F Ratios of Self-Integration Scores According to Attachment Style (Study 4)

\begin{tabular}{|c|c|c|c|c|}
\hline \multirow[b]{2}{*}{ Integration score } & \multicolumn{3}{|c|}{ Attachment style } & \multirow[b]{2}{*}{$F(2,57)$} \\
\hline & Secure & Avoidant & Ambivalent & \\
\hline Similarity & & & & 2.44 \\
\hline$M$ & 2.96 & 2.93 & 2.75 & \\
\hline$S D$ & 0.37 & 0.22 & 0.38 & \\
\hline Mutual influence & & & & $5.16^{* *}$ \\
\hline$M$ & 3.66 & $3.19^{\mathrm{a}}$ & $3.21^{\mathrm{a}}$ & \\
\hline$S D$ & 0.47 & 0.58 & 0.50 & \\
\hline Trade-off & & & & $5.49^{* *}$ \\
\hline$M$ & 3.69 & $3.26^{\mathrm{a}}$ & $3.24^{\mathrm{a}}$ & \\
\hline$S D$ & 0.34 & 0.54 & 0.53 & \\
\hline Joint interaction & & & & $7.61^{* *}$ \\
\hline$M$ & 3.94 & $3.16^{\mathrm{a}}$ & $3.13^{\mathrm{a}}$ & \\
\hline$S D$ & 0.63 & 0.88 & 0.68 & \\
\hline MANOVA $(8,108)$ & & & & $2.51^{*}$ \\
\hline
\end{tabular}

Note. MANOVA = multivariate analysis of variance.

a Significantly different from secure participants.

${ }^{*} p<.05$. ${ }^{* *} p<.01$.

Taken together, the findings of Studies 3 and 4 reveal that secure people have a highly differentiated and integrated selfstructure, avoidant people have a differentiated but less wellintegrated structure, and anxious-ambivalent people have a less differentiated structure. Of course, these findings may reflect broader differences in cognitive organization or skills. Moreover, they should be subject to the influence of response strategies or set. Further research should attempt to deal with these issues and to replicate the current findings using other techniques, such as thematic analysis of personal narrative (Tetlock, 1983; Woike, 1994).

\section{Study 5}

Study 5 examined differences among attachment groups in the levels of discrepancies among three domains of the selfstructure: actual self, ideal self, and ought self (Higgins, 1987). For this purpose, participants completed the Selves Questionnaire (Higgins et al., 1985), in which they listed 10 traits associated with the three assessed self-domains. Then semantic and quantitative discrepancies were calculated between each pair of domains ( actual self-ideal self, actual selfought self, ideal self-ought self). I predicted that ambivalent and avoidant people would show higher self-discrepancy scores than would secure people.

\section{Method}

Participants. Eighty high school students ( 46 females and 34 males ranging in age from 16 to 18 ) participated in the study without any reward.

Materials and procedure. Participants were approached in the classroom and tested in groups of around 30 . They were told that they would participate in a study on self-perception. They completed the attachment style scale (see Study 1 ) and the Selves Questionnaire in a random order. Fifty-five percent of the participants classified themselves as secure $(N=44), 25 \%$ as avoidant $(N=20)$, and $20 \%$ as ambivalent $(N=16)$.

In the Selves Questionnaire, participants received three sheets and listed on each 10 attributes that define their actual self, ideal self, or ought self from their own point of view. Higgins's (1982) definitions of each domain were provided at the top of each sheet. Participants were then asked to rate the extent to which they actually, ideally, or ought to possess the attribute, on a scale that ranged from 1 (a little) to 4 (extremely).

The discrepancy between two domains was quantified on the basis of Higgins et al.'s (1986) procedure. First I counted (a) the number of semantic mismatches-the number of attributes in one domain that had semantic opposites on the other domain, (b) the number of mismatches of extent-the number of synonyms that appeared in two domains and differed in extent by more than one, and (c) the number of matches-the number of synonyms that appeared in two domains and did not differ in extent by more than one. Semantic matches and mismatches were operationalized using a Hebrew dictionary. Then semantic mismatches were given a weight of 2 , mismatches of extent and matches were given a weight of 1 , the two types of mismatches were summed, and the matches were subtracted from the sum. On this basis, three discrepancy scores were computed (actual-ideal, actual-ought, and ideal-ought), with higher scores reflecting higher self-discrepancies. To test the reliability of this procedure, two raters independently scored 20 randomly selected self-domain pairs. The interrater correlation was .87 .

\section{Results and Discussion}

A multivariate analysis of variance (MANOVA) yielded a significant effect for attachment style, $F(6,150)=4.75, p<.01$. One-way ANOVAs indicated that this effect was significant in all the three discrepancy scores ( see $F$ ratios in Table 4). Scheffe post hoc tests indicated that both avoidant and anxious-ambivalent participants reported higher self-discrepancies than did secure participants (see means in Table 4). No significant difference was found between avoidant and anxious-ambivalent participants. As expected, secure people showed fewer discrepancies between their actual self and the two representations that serve as motivational guides-ideal self and actual selfthan insecure participants.

It is interesting to note that the relatively high ideal-ought discrepancy exhibited by avoidant and anxious-ambivalent people might reflect the existence of a double approach-avoidance conflict (Van Hook \& Higgins, 1988), in which meeting one self-guide implies the failure to meet another self-guide. Moreover, this discrepancy may be related to feelings of uncertainty and confusion about personal identity as well as to the internalization of inconsistent or even contradictory parental demands and guides. Further research should explore the attachment-related developmental source of self-guide-self-guide discrepancies.

\section{Study 6}

Though no ad hoc predictions can be made about differences between attachment groups in discrepancies between standpoints of the self, this issue can shed light on the way people differing in attachment style internalize reactions of significant others to them. Moreover, it could provide complementary in- 
Table 4

Means, SDs, and F Ratios of Self-Discrepancy Scores According to Attachment Style (Study 5)

\begin{tabular}{lrlll}
\hline & \multicolumn{3}{c}{ Attachment style } \\
\cline { 2 - 4 } $\begin{array}{c}\text { Self-discrepancy } \\
\text { scores }\end{array}$ & Secure & Avoidant & Ambivalent & $F(2,77)$ \\
\hline Actual self-ideal self & -1.18 & $0.95^{\mathrm{a}}$ & $1.31^{\mathrm{a}}$ & $6.42^{* *}$ \\
$M$ & 2.48 & 3.19 & 3.40 & \\
$S D$ & -1.34 & $2.20^{\mathrm{a}}$ & $2.19^{\mathrm{a}}$ & $11.80^{* *}$ \\
Actual self-ought self & 3.85 & 2.50 & 4.13 & \\
$M$ & -0.97 & $1.10^{\mathrm{a}}$ & $2.31^{\mathrm{a}}$ & $7.65^{* *}$ \\
$S D$ & 2.81 & 3.17 & 3.81 & \\
Ideal self-ought self & & & & $4.75^{* *}$ \\
$M$ & & &
\end{tabular}

Note. MANOVA $=$ multivariate analysis of variance.

a Significantly different from secure participants.

** $p<.01$.

formation about the coherence of the self-structure of the three attachment groups. For these reasons, Study 6 explored the association of attachment style with the level of discrepancy between participants' own view of the actual self and participants' perception of the standpoint of three significant othersmother, father, and friend-about the actual self. Participants completed the Selves Questionnaire in reference to the above four standpoints, and relevant discrepancies were calculated.

\section{Method}

Participants. Eighty-four high school students ( 53 females and 31 males ranging in age from 16 to 18 ) volunteered to participate in the study without any reward.

Materials and procedure. The instructions, material, and procedure were identical to those described in Study 5. For the mother, father, and friend questionnaires, participants were instructed to think about the way their mother/father/friend perceives his or her actual self. The order of the questionnaires was counterbalanced. In the attachment style scale, $61 \%$ of the participants classified themselves as secure ( $N=$ $51), 25 \%$ as avoidant $(N=21)$, and $14 \%$ as ambivalent $(N=12)$. On the basis of participants' answers to the Selves Questionnaires, three discrepancy scores were computed for each participant: one's ownmother standpoints, one's own-father standpoints, one's own-friend standpoints. Higher scores reflect higher discrepancy between two standpoints.

\section{Results and Discussion}

The MANOVA yielded a significant effect for attachment style, $F(6,158)=5.93, p<.01$. One-way ANOVAs indicated that this effect was significant in all the three discrepancy scores (see $F$ ratios in Table 5). Scheffe tests showed that avoidant and anxious-ambivalent participants reported higher discrepancies between their own standpoint and other's standpoint than secure participants ( see means in Table 5). No significant difference was found between avoidant and ambivalent participants.

In the next step of analysis, the quality of the above discrepancies was assessed. That is, whether a mismatch reflects the belief that a significant other's view of the participant's self is more positive than the participant's own self-view or the belief that a significant other has a more negative view. Two judges (psychology students), unaware of the participants' attachment styles, independently read the traits listed by the participants in each standpoint and marked whether they were positive, negative, or neutral. Judges agreed in more than $90 \%$ of the cases. In cases of disagreement, the attribute was marked as neutral. Next, a positivity score was computed for each standpoint by subtracting the number of negative attributes from the number of positive attributes listed in the particular standpoint. Higher scores reflect a more positive image of the actual self. Because the main interest was the discrepancy between the participant's view and the standpoint of others, the scores of mother, father, and friend standpoints were averaged.

A two-way ANOVA for attachment style and standpoint on the self (participant's own, other), with the last variable treated as a within-subject measure, yielded a significant interaction, $F(2,81)=8.59, p<.01$. Simple main effect tests for repeated measures revealed the following differences: For ambivalent participants, their own perspective of the self was less positive than the perceived standpoint of significant others, $F(1,81)=$ $5.73, p<.05$ ( $M \mathrm{~s}=1.75$ vs. 2.78 ). In contrast, for avoidant participants, their own view of the self was more positive than the perceived standpoint of significant others, $F(1,81)=8.08$, $p<.01(M \mathrm{~s}=2.86$ vs. 1.84$)$. No significant difference was found in the secure group $(M \mathrm{~s}=2.53$ vs. 2.49$)$.

Relative to secure people, both avoidant and anxious-ambivalent people have more discrepancies between their own selfview and the view they believe that a significant other has of them. However, the insecure groups differed in the quality of this discrepancy: Whereas avoidant people believed that a significant other has a more negative view of themselves, anxiousambivalent people believed that a significant other has a more positive view.

Taken as a whole, the findings of Studies 5 and 6 indicate that secure people have a more coherent self-structure than do 
Tabie 5

Means, SDs, and F Ratios of Self-Discrepancy Scores According to Attachment Style (Study 6)

\begin{tabular}{lcccc}
\hline & \multicolumn{3}{c}{ Attachment style } \\
\cline { 3 - 4 } Discrepancy between standpoints & Secure & Avoidant & Ambivalent & $F(2,81)$ \\
\hline Participant's own-mother standpoint & & & & $7.82^{* *}$ \\
$M$ & -1.20 & $2.09^{\mathrm{a}}$ & $3.08^{\mathrm{a}}$ & \\
$S D$ & 3.78 & 5.15 & 3.96 & \\
Participant's own-father standpoint & -2.00 & $1.01^{\mathrm{a}}$ & $2.33^{\mathrm{a}}$ & \\
$M$ & 2.88 & 5.51 & 2.96 & \\
$S D$ & -1.11 & $2.18^{* *}$ & $17.54^{* *}$ \\
Participant's own-friend standpoint & 2.57 & 4.49 & $4.75^{\mathrm{a}}$ & \\
$M$ & & & 4.41 & \\
$S D$ & & & & $5.92^{* *}$ \\
MANOVA (6, 158) & & &
\end{tabular}

Note. MANOVA $=$ multivariate analysis of variance.

a Significantly different from secure participants.

** $p<.01$.

insecure people. However, one should take into account that these findings were based on global descriptions of the self. Further research should ask participants to describe the domains and standpoints of more specific self-aspects and evaluate whether the observed differences are generalized over different self-aspects or circumscribed to attachment-related self-aspects (e.g., "myself as a friend").

\section{General Discussion}

Taken as a whole, the current findings support the hypothesized associations between attachment style and the content and structure of self-representations. The findings also highlight the need for assessing different aspects of the self-structure rather than the global concept of self-esteem. In fact, attachment groups differed not only in the positivity of their self-view but also in other structural dimensions of the self.

The findings for secure people emphasize the importance of a warm attachment relationship for the development of a positive, coherent, and well-organized self-structure. These people described themselves in positive terms yet admitted negative selfattributes (Studies 1 and 2), exhibited a highly differentiated and integrated self-schema (Studies 3 and 4), and revealed relatively low discrepancies between domains and standpoints of the self (Studies 5 and 6 ). This pattern may follow from the secure base of accepting and supporting attachment figures, which may lead to the creation of a balanced self-view by highlighting positive self-representations and encouraging people to tolerate weak points of the self. Moreover, it may lead to a coherent self-structure by promoting a self-view that meets internalized guides and matches the positive view that secure people believe others have of them.

The observed self-schemas of secure people concurs with a growing body of research connecting security in attachment to constructive coping (e.g., Mikulincer et al., 1993). The positive view secure people have of themselves may allow them to confront life problems with optimism and a sense of mastery, whereas their ability to organize experience into differentiated, nonaffective categories may allow them to encapsulate distress and to prevent its spreading to the entire self-structure. In addition, the capacity of secure people to explore both strong and weak points of the self may be manifested in setting realistic goals and plans, and flexible adjustment of schemata and actions to reality constraints. Finally, the coherence of their selfstructure may prevent the experience of overwhelming distress every time they fail in meeting their ideal-ought standards.

Although some authors have claimed that the self-view of avoidant people resembles that of secure people (Bartholomew \& Horowitz, 1991), the current findings present a more complex picture. On the one hand, avoidant people were similar to secure people in that they had a highly positive and differentiated self-structure that was not pervaded by emotional experience (Studies 1 and 3). On the other hand, avoidant people differed from secure people in that they showed low accessibility to negative self-aspects, did not perceive connections and interactions between differentiated self-aspects, and revealed high discrepancies between domains and standpoints of the self (Studies 2, 4, and 6). In general, the positive self-view of avoidant people appears to lack balance, integration, and inner coherence.

The above pattern of self-representations may result from both the basic insecurity of avoidant people and their habitual way of coping with it. Their basic insecurity was manifested in the relatively high discrepancies between domains and standpoints of the self. Their history of an insecure relationship with rejecting parents (e.g., Shaver \& Hazan, 1993) may lead avoidant people to believe that they are not the type of person their parents think they ought to be or the person for whom their parents had hoped. The internalization of this sense of failure may be reflected in (a) the development of standards that are so far from what one actually is that they cannot be met without destroying core aspects of the self and (b) the belief that significant others have a negative view of one's self.

The strategy avoidant people typically use in coping with their basic insecurity was directly manifested in the low accessi- 
bility of negative self-attributes and the inability to integrate different aspects of the self. Mikulincer and Orbach (1995) labeled this strategy nondifferentiated defensiveness. It includes denial of insecurity, devaluation of events that cause painful feelings, and suppression of negative affects and memories. In the current study, this strategy might underlie the development of a nonintegrated self-structure, in which some important aspects of personal experience are suppressed and precluded from awareness.

Along the above reasoning, the greater accessibility of positive self-attributes exhibited by avoidant people might not imply the existence of truly high self-esteem. Rather, it may imply that their self-esteem is so low and fragile that they cannot tolerate discovery of the slightest flaw. This idealization of the self seems to be a defense against the experience of rejection by others on the recognition of one's imperfections. Accordingly, the high self-differentiation of avoidant people might in part reflect the action of repression, by which information that is not accepted as part of the self is dissociated from other positive self-aspects. This line of thinking emphasizes the need for more subtle measures of self-representation that could bypass the defensive armor of avoidant people and reveal their basic sense of rejection and worthlessness.

If this reasoning is true, one can ask why this strategy was not manifested in avoidant participants' self-discrepancies. This may be due to methodological reasons. In the Selves Questionnaire, participants were not asked to recognize or admit selfdiscrepancies but only to list traits of various self-domains and standpoints. Discrepancies were calculated by external judges. Asking avoidant participants directly about their perceived level of self-discrepancies might have activated their habitual defensive strategies, therefore resulting in the negation of any selfdiscrepancy.

Anxious-ambivalent participants exhibited a negative, simple, and less integrated self-structure. Their self-structure was pervaded by negative self-attributes and affects (Studies 1-3), and it was characterized by low differentiation and low integration of self-representations (Studies 3 and 4 ) as well as by high discrepancies between domains and standpoints of the self (Studies 5 and 6). This pattern of findings appears to reflect the basic attachment insecurity of anxious-ambivalent people and their difficulties in regulating the resulting distress. Their experience of rejection and nonacceptance by attachment figures is directly manifested in the internalization of a negative self-image that is far from what they want or feel they ought to be as well as from what they believe significant others expect from them. Their difficulty in regulating distress was manifested in the high accessibility of negative self-attributes and the excessive use of affective criteria in organizing self-relevant information. Anxious-ambivalent people may feel overwhelmed by negative thoughts and feelings and then may lack the resources needed for developing a complex and coherent self-structure.

It is important to note that the pattern of findings for anxious-ambivalent participants parallels that of depressed people found in previous studies (e.g., Higgins, 1987; Kuiper \& Derry, 1982; Pietromonaco, 1985). This parallelism is supported by prior findings that anxious-ambivalent people are likely to experience depressed mood (Mikulincer et al., 1993). Further studies should examine whether there are any aspects of selfstructure that are associated specifically with anxious-ambivalent attachment and not necessarily with depression.

The current findings appear to support Bartholomew and Horowitz's ( 1991) idea that the model of the self is a fundamental dimension of the individual's attachment style. However, the findings present a more complex picture than that implied by a positive-negative dichotomy of the self (Bartholomew \& Horowitz, 1991). For example, the positive view that secure people have of themselves seems to live together with the fact that negative self-attributes are active components of their self-structure. Moreover, although secure people have accessible bad attributes, they show low self-discrepancies. In contrast, avoidant people, who admit only positive attributes, show high self-discrepancies that reflect a sense of failure in meeting self-guides and inner conflicts with internalized representations of attachment figures. Clearly, the findings demand a more complex conceptualization of models of the self related to attachment styles.

Future conceptualizations of working models of the self should also take into account that they mirror representations of attachment experiences. The self-view of secure people mentally reproduces their positive attachment experiences, wherein they could tolerate distress, separation, and other negative episodes because of their confidence in the availability of loving attachment figures. The incoherent self-view of avoidant people may be a natural continuation of the dissociative process that excludes information related to attachment needs and negative attachment experiences. Finally, the negative self-image of anxious-ambivalent people mirrors their negative attachment experiences wherein they feel that they bring about only negative outcomes and are unable to prevent the loss of positive outcomes.

Some methodological caveats should be considered in discussing the current findings. First, the sample included young adolescents who probably had limited experience in romantic relationships and who may show exaggerated worries about selfpresentation and other self-identity issues. Further studies should attempt to replicate the current findings in older samples. Second, the cross-sectional design of the studies prevents making any statement about the direction of effects and about the mechanisms that underlie the connection between attachment style and self-structure. Although Bowlby (1973) proposed that attachment experiences shape self-image, it might be that the reverse is the case or that other factors shape both attachment style and self-image. Third, the present studies bring no information about concrete, behavioral-based selfrepresentations as well as about concrete patterns of interactions with specific attachment figures. Fourth, further studies should pay more attention to the measurement of attachment working models, including parent-child attachment, and to alternative taxonomies of attachment style.

Beyond the above caveats, the present series of studies makes a number of important contributions to the research on adult attachment. It illustrates the importance of an attachment analysis to understand people's self-views and the way they organize self-relevant information. The findings also provide empirical support for Bowlby's (1973) notion that people incorporate at- 
tachment experiences into working models of the self and carry these models into new experiences.

\section{References}

Ainsworth, M. D. S., Blehar, M. C., Waters, E., \& Wall, S. (1978). Patterns of attachment: A psychological study of the strange situation. Hillsdale, NJ: Erlbaum.

Anderson, N. H. (1968). Likableness ratings of 555 personality trait words. Journal of Personality and Social Psychology, 9, 272-279.

Bargh, J. A., \& Tota, M. E. (1988). Context-dependent processing in depression: Accessibility of negative constructs with regard to self but not others. Journal of Personality and Social Psychology, 54, 924939.

Bartholomew, K., \& Horowitz, L. (1991). Attachment styles among young adults: A test of a four-category model. Journal of Personality and Social Psychology, 61, 226-244.

Beck, A. T. (1976). Cognitive therapy and the emotional disorders. New York: International University Press.

Bowlby, J. (1969). Attachment and Loss: Attachment. New York: Basic Books.

Bowlby, J. (1973). Attachment and Loss: Separation, anxiety and anger. New York: Basic Books.

Bowlby, J. (1980). Attachment and Loss: Sadness and depression. New York: Basic Books.

Bowlby, J. (1988). A secure base: Clinical applications of attachment theory. London: Routledge and Kegan Paul.

Brennan, K. A., \& Shaver, P. R. (in press). Dimensions of adult attachment and the dynamics of romantic relationships. Personality and Social Psychology Bulletin.

Cassidy, J. (1988). Child-mother attachment and the self in six-yearolds. Child Development, 59, 121-134.

Collins, N. L., \& Read, S. J. (1990). Adult attachment, working models, and relationship quality in dating couples. Journal of Personality and Social Psychology, 58, 644-663.

Derry, P., \& Kuiper, N. A. (1981). Schematic processing and self-reference in clinical depression. Journal of Abnormal Psychology, 90, 286297.

Feeney, J. A., \& Noller, P. (1990). Attachment style as a predictor of adult romantic relationships. Journal of Personality and Social Psychology, 58, 281-291.

Ferguson, T., Rule, B., \& Carlson, D. (1983). Memory for persistently relevant information. Journal of Personality and Social Psychology, 44, 251-261.

Griffin, D., \& Bartholomew, K. (1994). Models of the self and other: Fundamental dimensions underlying measures of adult attachment. Journal of Personality and Social Psychology, 67, 430-445.

Hazan, C., \& Shaver, P. (1987). Romantic love conceptualized as an attachment process. Journal of Personality and Social Psychology, 52, $511-524$.

Higgins, E. T. ( 1987). Self-discrepancy: A theory relating self and affect. Psychological Review, 94, 319-340.

Higgins, E. T., Bond, R. N., Klein, R., \& Strauman, T. J. (1986). Selfdiscrepancies and emotional vulnerability: How magnitude, accessibility and type of discrepancy influence affect. Journal of Personality and Social Psychology, 51, 5-15.

Higgins, E. T., Klein, R., \& Strauman, T. J. (1985). Self-concept discrepancy theory: A psychological model for distinguishing among different aspects of depression and anxiety. Social Cognition, 3, 5176.

Kihlstrom, J. F., \& Cantor, N. (1984). Mental representations of the self. In L. Berkowitz (Ed.), Advances in experimental social psychology (Vol. 17, pp. 1-47). New York: Academic Press.
Kobak, R. R., \& Sceery, A. (1988). Attachment in late adolescence: Working models, affect regulation, and representations of self and others. Child Development, 59, 135-146.

Kuiper, N. A., \& Derry, P. (1982). Depressed and nondepressed content self-reference in mild depressives. Journal of Personality, 50, 67-80.

Kuiper, N. A., Olinger, L. J., MacDonald, M. R., \& Shaw, B. F. (1985). Self-schema processing of depressed and nondepressed content: The effects of vulnerability to depression. Social Cognition, 3, 77-93.

Linville, P. W. (1985). Self-complexity and affective extremity: Don't put all of your eggs in one cognitive basket. Social Cognition, 3, 94120.

Markus, H. (1977). Self-schemata and processing information about the self. Journal of Personality and Social Psychology, 35, 63-78.

Markus, H., \& Wurf, E. (1987). The dynamic self-concept: A social psychological perspective. Annual Review of Psychology, 38, 299-337.

Mathews, A., \& MacLeod, C. (1985). Selective processing of threat cues in anxiety states. Behavior Research and Therapy, 23, 563-569.

Mikulincer, M., \& Erev, I. (1991). Attachment styles and the structure of romantic love. British Journal of Social Psychology, 30, 273-291.

Mikulincer, M., Florian, V., \& Tolmacz, R. (1990). Attachment styles and fear of personal death: A case study of affect regulation. Journal of Personality and Social Psychology, 58, 273-280.

Mikulincer, M., Florian, V., \& Weller, A. (1993). Attachment styles, coping strategies, and post-traumatic psychological distress: The impact of the Gulf War in Israel. Journal of Personality and Social Psychology, 64, 817-826.

Mikulincer, M., \& Orbach, I. (1995). Attachment styles and repressive defensiveness: The accessibility and architecture of affective memories. Journal of Personality and Social Psychology, 68, 917-925.

Pietromonaco, P. R. (1985). The influence of affect on self-perception in depression. Social Cognition, 3, 121-134.

Pietromonaco, P. R., \& Carnelley, K. B. (1994). Gender and working models of attachment: Consequences for perceptions of self and romantic relationships. Personal Relationships, 1, 63-81.

Rogers, T. B. (1981). A model of the self as an aspect of the human information processing system. In N. Cantor \& J. F. Kihlstrom (Eds.), Personality, cognition, and social interaction (pp. 193-214). Hillsdale, NJ: Erlbaum.

Schroder, H. M., Driver, M. J., \& Streufert, S. (1967). Human information processing. New York: Holt, Rinehart \& Winston.

Segal, Z. V. ( 1988). Appraisal of the self-schema in cognitive models of depression. Psychological Bulletin, 103, 147-162.

Segal, Z. V., \& Vella, D. D. (1990). Self-schema in major depression: Replication and extension of a priming methodology. Cognitive Therapy and Research, 14, 161-176.

Shaver, P. R., \& Hazan, C. (1993). Adult romantic attachment: Theory and evidence. In D. Perlman \& W. Jones (Eds.), Advances in personal relationships (Vol. 4, pp. 29-70). London: Jessica Kingsley.

Simpson, J. A. ( 1990). The influence of attachment styles on romantic relationships. Journal of Personality and Social Psychology, 59, 273280.

Simpson, J. A., Rholes, W. S., \& Nelligan, J. S. (1992). Support seeking and support giving within couples in an anxiety-provoking situation: The role of attachment styles. Journal of Personality and Social Psychology, 62, 434-446.

Sroufe, L. A., \& Fleeson, J. (1986). Attachment and the construction of relationships. In W. Hartup \& Z. Rubin (Eds.), Relationships and development (pp. 51-71). Cambridge, England: Cambridge University Press.

Strauman, T. J., \& Higgins, E. T. (1987). Automatic activation of selfdiscrepancies and emotional syndromes: When cognitive structures influence affect. Journal of Personality and Social Psychology, 53, 1004-1014. 
Streufert, S., \& Streufert, S. C. (1978). Behavior in the complex environment. Washington, DC: V. H. Winston.

Stroop, J. R. (1938). Factors affecting speed in serial verbal reactions. Psychological Monographs, 50, 38-48.

Tetlock, P. E. (1983). Accountability and complexity of thought. Journal of Personality and Social Psychology, 45, 74-83.

Tetlock, P. E., Peterson, R. S., \& Berry, J. M. (1993). Flattering and unflattering personality portraits of integratively simple and complex managers. Journal of Personality and Social Psychology, 64, 500-511.

Tetlock, P. E., \& Suedfeld, P. (1988). Integrative complexity coding of verbal behavior. In C. Antaki (Ed.), Lay explanation (pp. 43-59). Beverly Hills, CA: Sage.

Van Hook, E., \& Higgins, E. T. (1988). Self-related problems beyond the self-concept: Motivational consequences of discrepant self-guides. Journal of Personality and Social Psychology, 55, 625-633.

Warren, R. E. (1972). Stimulus encoding and memory. Journal of Experimental Psychology, 94, 90-100.

Winer, B. J. (1971). Statistical principles in experimental designs. New York: McGraw-Hill.

Woike, B. A. (1994). The use of differentiation and integration processes: Empirical studies of "separate" and "connected" ways of thinking. Journal of Personality and Social Psychology, 67, 142-150.

Woike, B. A., \& Aronoff, J. (1992). Antecedents of complex social cognition. Journal of Personality and Social Psychology, 63, 97-104.

Received November 21, 1994

Revision received April 14, 1995

Accepted April 25, 1995

\section{American Psychological Association SUBSCRIPTION ClaIMS INFORMATION}

Today's Date:

We provide this form to assist members, institutions, and nonmember individuals with any subscription problems. With the appropriate information we can begin a resolution. If you use the services of an agent, please doNOT duplicate claims through them and directly to us. PLEASE PRINT CLEARLY AND IN INK IF POSSIBLE.

\begin{tabular}{l}
\hline PRINT FULL NAME OR KEY NAME OF INSTTIUTION \\
\begin{tabular}{l} 
ADDRESS \\
\hline CITY
\end{tabular}
\end{tabular}

YOUR NAME AND PHONE NUMBER

TITLE

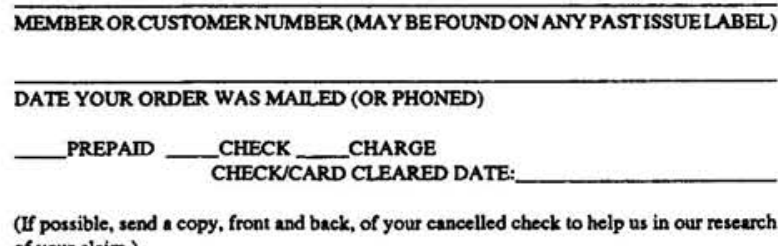
of your claim.)

ISSUES: _ MISSING DAMAGED

VOLUME OR YEAR
NUMBER OR MONTH

Thank you. Once a claim is received and resolved, delivery of replacement issues routinely takes 4-6 weeks.

DATE RECEIVED:

ACTION TAKEN:

STAFF NAME:
DATE OF ACTION:

INV. NO. \& DATE:

LABEL NO. \& DATE:

Send this form to APA Subscription Claims, 750 First Street, NE, Washington, DC 20002-4242

PLEASE DO NOT REMOVE. A PHOTOCOPY MAY BE USED. 